\title{
Investigation of Different Regimes of Beer Fermentation with Free and Immobilized Cells
}

\author{
Ivan Petelkov1, Vesela Shopska1, Rositsa Denkova-Kostova², Georgi Kostov ${ }^{1 *}$, \\ Velislava Lyubenova ${ }^{3}$ \\ ${ }^{1}$ Department of Wine and Beer Technology, Technological Faculty, University of Food Technologies, \\ 26 Maritza Blvd., 4000 Plovdiv, Bulgaria \\ 2 Department of Biochemistry and Molecular Biology, Technological Faculty, University of Food Technologies, \\ 26 Maritza Blvd., 4000 Plovdiv, Bulgaria \\ ${ }^{3}$ Institute of Robotics, Bulgarian Academy of Sciences, P. O. Box 79, 1113 Sofia, Bulgaria \\ * Corresponding author, e-mail: george_kostov2@abv.bg
}

Received: 08 February 2019, Accepted: 17 April 2019, Published online: 31 December 2019

\begin{abstract}
Three different kinetic models - Monod's model, Monod's model with substrate inhibition, and Monod's model with substrate and product inhibition were developed for studying of beer fermentation with free and immobilized cells at different main fermentation and maturation temperatures. The most accurate model was Monod's model with substrate and product inhibition. It showed that maturation temperature had no effect on primary metabolism but it affected significantly the secondary metabolites production. In regard to carbonyl compounds and esters, the increase in maturation temperature led to different trends for free and immobilized cells. Regarding the higher alcohols, the increase in maturation temperature resulted in increase in their yield coefficients for both immobilized and free cells. A sensory evaluation of beers produced with free and immobilized cells were also carried out and the results showed similar results for two beer types.
\end{abstract}

Keywords

beer fermentation regimes, kinetic of fermentation, modeling, immobilized cells

\section{Introduction}

Fermentation and maturation are the longest stages in beer production. Therefore, in such a competitive market, the potential time-savings proposed by immobilized cells technologies (ICT) have to be taken into account $[1,2]$. A major challenge for the successful industrial scale application of ICT is to control the beer flavor profile during combined primary and secondary fermentation [3]. The beer flavor depends significantly of yeast metabolism and fermentation conditions. Higher alcohols, esters, aldehydes and vicinal diketones (VDKs) are yeast by-products which contribute to the final quality of the beer. While higher alcohols and esters have a positive effect on beer flavor, VDKs and aldehydes are often considered as off-flavors [4]. The increase in fermentation temperature accelerates the formation of fusel alcohols, esters, aldehydes, and VDKs. Nevertheless, the rising temperature does not result in higher VDKs and aldehyde concentration in final beer because of their reduction [2-7]. In the terms of immobilization, yeast metabolism can be changed because of considerable mass transfer limitations that can occur. Therefore, successful exploitation of ICT needs a thorough understanding of mass transfer and intrinsic yeast kinetic behavior of these systems [8].

The aim of this study is to investigate the mechanism and kinetic of beer fermentations with free and immobilized cells Saccharomyces carlsbergensis Saflager S-23 at three different fermentation regimes. Three mathematical models were developed for the selection of the most proper fermentation regime with immobilized cells. Sensorial analyses were also made to compare the flavor of traditional produced beer and ICT produced beer. 


\section{Materials and methods}

\subsection{Yeast strains}

Beer fermentation was carried out using a bottom-fermenting dry yeast Saccharomyces pastorianus (carlsbergensis) Saflager S-23 (Fermentis, France).

\subsection{Wort}

Wort with original extract $(O E) 13 \pm 0.5^{\circ} \mathrm{P}$ was produced in $20 \mathrm{~L}$ laboratory scale brewery (Braumeister, Germany). $4 \mathrm{~kg}$ malt and $0.5 \mathrm{~kg}$ barley were mixed with water at ratio 1:4. Mashing was conducted by increasing the temperature by $1{ }^{\circ} \mathrm{C} / \mathrm{min}$ and by maintaining the following temperature rests: $20 \mathrm{~min}$ at $45^{\circ} \mathrm{C}, 30 \mathrm{~min}$ at $52{ }^{\circ} \mathrm{C}, 40 \mathrm{~min}$ at $63{ }^{\circ} \mathrm{C}, 25 \mathrm{~min}$ at $72{ }^{\circ} \mathrm{C}$ and $1 \mathrm{~min}$ at $78{ }^{\circ} \mathrm{C}$. Lautering and boiling were also conducted in the same Braumeister. Boiling duration was approximately $1 \mathrm{~h}$ and Nugget hop granules were added to the wort at the beginning of the process. After the hot trub removal, the wort was cooled to the fermentation temperature.

\subsection{Immobilization}

The cells were immobilized in a $3 \% \mathrm{Ca}$ alginate gel. After autoclaving the alginate solution for $20 \mathrm{~min}$ at $120{ }^{\circ} \mathrm{C}$, the solution was mixed with the cell suspension to obtain a cell concentration of $10^{7} \mathrm{cfu} \cdot \mathrm{mL}^{-1}$ of gel. This suspension was forced through a syringe needle by means of peristaltic pump and dropped into $2 \%(\mathrm{w} / \mathrm{v}) \mathrm{CaCl}_{2}$ solution. The beads were left for $30 \mathrm{~min}$ in calcium solution and then numbers of beads were placed into $0.2 \%(\mathrm{w} / \mathrm{v})$ chitosan solution in $1 \%$ acetic acid (v/v). Alginate beads stayed in chitosan solution for $60 \mathrm{~min}$. Chitosan-alginate beads are washed with saline. Then the beads were transferred in $0.05 \mathrm{M} \mathrm{Na}$-citrate solution for $30 \mathrm{~min}$ for constructing microcapsules with liquid core. Chitosan-alginate beads with liquid core were washed with saline [9].

\subsection{Wort fermentation}

The fermentation of all variants was carried in plastic bottles, with a volume of $500 \mathrm{~mL}$, equipped with an airlock system. The $400 \mathrm{~mL}$ of wort was placed into bottles and inoculated with a yeast suspension at a concentration of $10^{7} \mathrm{cfu} . \mathrm{mL}^{-1}$. For the variants with immobilized cells, the mass of microcapsules was $15 \mathrm{~g}$ for $400 \mathrm{~mL}$ wort. Three different fermentation regimes were used - main fermentation at $12{ }^{\circ} \mathrm{C}$ and $14{ }^{\circ} \mathrm{C}, 8^{\circ} \mathrm{C}$ and $20^{\circ} \mathrm{C}$, respectively for maturation. The fermentation temperature was increased when the difference between attenuation limit and apparent attenuation was approximately $20 \%$.

\subsection{Analytical methods and procedures}

1. Standard methods according to EBC [10]

2. Determination of metabolites: Esters, aldehydes and fusel alcohol in beer were quantified according to [11].

3. Determination of biomass: Biomass concentration was calculated according to [9].

\subsection{Mathematical and statistical analyses}

Mathematical and statistical analyses were made according to Eqs. (1) to (6) [12]. The difference between free and immobilized cells fermentation was determined by the efficiency coefficients $-\eta$, representing the ratio between an immobilized cells fermentation parameter and the same parameter for free cells fermentation.

$$
\mid \begin{aligned}
& \frac{d B}{d \tau}=\mu B \\
& \frac{d E}{d \tau}=q_{E} B \\
& \frac{d R E}{d \tau}=-\frac{1}{Y_{B / R E}} \frac{d B}{d \tau}-\frac{1}{Y_{E / R E}} \frac{d A}{d \tau} \\
& \frac{d E s t}{d \tau}=Y_{E s t} \mu B \\
& \frac{d H A}{d \tau}=Y_{H A} \mu X \\
& \frac{d A l d}{d \tau}=Y_{A l d} \mu B-k_{A l d} B A l d \\
& \frac{d V D K}{d \tau}=Y_{V D K} \mu B-k_{V D K} B V D K
\end{aligned}
$$

Monod model

$$
\mu=\mu_{\max } \frac{R E}{K_{S B}+R E} ; \quad q_{E}=q_{E \max } \frac{R E}{K_{S A}+R E}
$$

Monod model with product inhibition

$$
\mu=\mu_{\max } \frac{R E}{K_{S B}+R E+\frac{A^{2}}{K_{S B i}}} ; \quad q_{E}=q_{E \max } \frac{R E}{K_{S A}+R E+\frac{A^{2}}{K_{S E i}}}
$$

Monod model with substrate and product inhibition

$$
\begin{gathered}
\mu=\mu_{\max }\left(1-\frac{A}{A_{M}}\right) \frac{R E}{K_{S B}+R E+\frac{R E^{2}}{K_{S B i}}} \\
q_{E}=q_{E \max }\left(1-\frac{A}{A_{M P}}\right) \frac{R E}{K_{S E}+R E+\frac{R E^{2}}{K_{S E i}}}
\end{gathered}
$$


$\frac{d R E_{i m}}{d \tau}=K_{L R E}\left(R E-R E_{i m}\right)-\left(\frac{\mu B}{Y_{B / R E}}\right)-\left(\frac{q B}{Y_{A / R E}}\right)$

$\frac{d E_{i m}}{d \tau}=-K_{L E}\left(E_{i m}-E\right)+\left(\frac{q B}{Y_{E / R E}}\right)$

$B$ - biomass concentration, g. $\mathrm{L}^{-1}$;

$A$ - alcohol concentration (product), g. $\mathrm{L}^{-1}$;

$R E$ - real extract (substrate), g. $\mathrm{L}^{-1}$;

$\tau$-time, h;

$Y_{A / R E}, Y_{B / R E}-$ yield coefficients;

$\mu$ - specific growth rate, $\mathrm{h}^{-1}$;

$\mu_{\max }-$ maximal specific growth rate, $\mathrm{h}^{-1}$;

$q_{E}-$ specific ethanol accumulation rate, g/(g.h);

$q_{E \max }-$ maximal specific ethanol accumulation rate, g/(g.h);

Est - ester concentration, mg. $\mathrm{L}^{-1}$;

$H A$ - higher alcohol concentration, mg. $\mathrm{L}^{-1}$;

Ald - aldehyde concentration, mg. $\mathrm{L}^{-1}$;

$V D K$ - vicinal diketones concentration, $\mathrm{mg} . \mathrm{L}^{-1}$;

$Y_{H A}, Y_{E s t}, Y_{A l d}, Y_{V D K}$ - yield coefficients of the corresponding metabolites, $\mathrm{mg} /(\mathrm{g} . \mathrm{h})$;

$k_{A l d}, k_{V D K}-$ reduction coefficients for aldehydes and vicinal diketones, $\mathrm{mg} /(\mathrm{g} . \mathrm{h})$;

$K_{S B}, K_{S E}-$ Monod constants, g.L. ${ }^{-1}$;

$K_{S B i}, K_{S E i}-$ inhibition constants, g.L $\mathrm{L}^{-1}$;

$A_{M}, A_{M A}$ - maximal alcohol concentration for full inhibition of the process, g. $\mathrm{L}^{-1}$;

$K_{L R E}, K_{L A}$ - global mass transfer coefficients for the substrate and the ethanol, $\mathrm{h}^{-1}$;

$R E_{i m}$ - substrate (real extract) concentration in the capsules, g.L ${ }^{-1}$;

$A_{I M}$ - alcohol concentration in the capsules (beads), g. $\mathrm{L}^{-1}$; $i$ (IC) - denoted process with immobilized cell

\subsection{Sensory analysis}

A sensory evaluation of the beers was carried out by a trained, 6-member tasting panel. The scores ranged from 0 (absent) to 10 (extremely strong). The nine attributes assessed were:

1. flowery,

2. fruity (banana, apple),

3. aroma intensity,

4. aroma purity,

5. structure (body),

6. malty,

7. acidity,

8. bitter,

9. deviation from beer character.

The results were depicted in a spider plot and the values were expressed as the mean of the two technological replicates.

\section{Results and discussion}

\subsection{Main fermentation at $12{ }^{\circ} \mathrm{C}$; maturation at $14^{\circ} \mathrm{C}$}

The main fermentation duration was about 120 hours for the free cells (FC) and 96 hours for the immobilized ones. The fermentation with immobilized cells (IC) started slowly because of the diffusion resistance of the capsules. Nevertheless, this fermentation ended about 24 hours earlier than the fermentation with free cells (Fig. 1). The extract consumption, biomass accumulation, and ethanol production were well described by the three models used.

The correlation coefficients varied between $92 \%$ and $98 \%$, which showed a high degree of similarity between the calculated and experimental data (Table 1) (hence only the results with the best model-the Monod's model
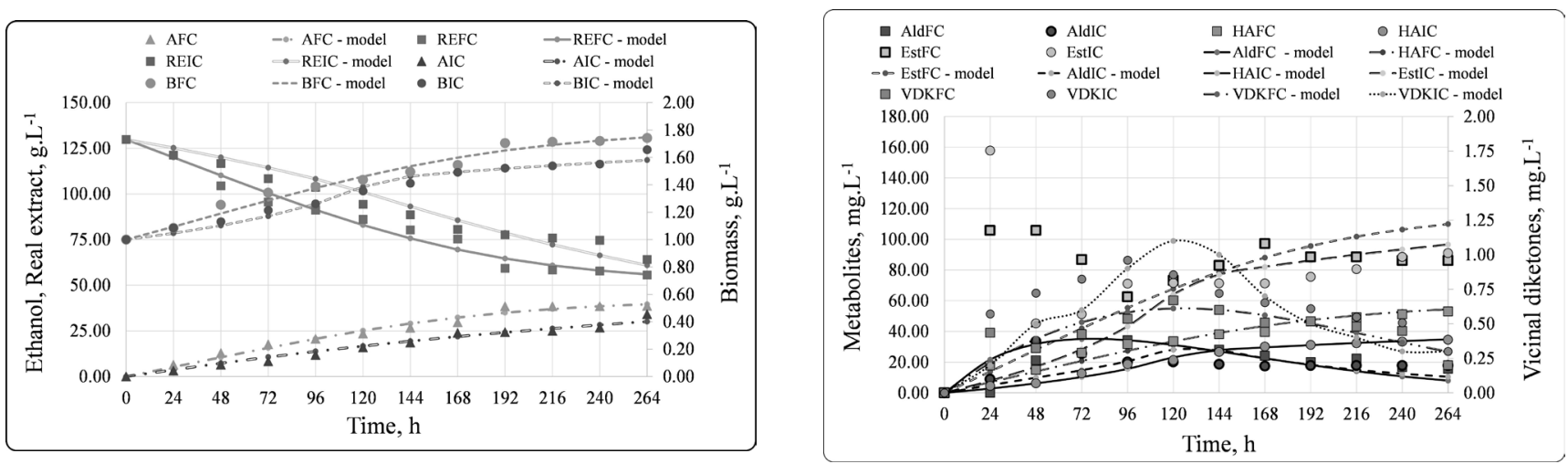

Fig. 1 The dynamics of the fermentation process with free and immobilized cells at $12{ }^{\circ} \mathrm{C} / 14{ }^{\circ} \mathrm{C}$; Legend: $B$ - biomass; $A$-alcohol; $R E$ - real extract; $V D K$ - vicinal diketones; Ald - aldehydes; $H A$ - higher alcohols; Est - esters; FC - free cells; IC - immobilized cells. 
supplemented with product and substrate inhibition are shown). The results of this experiments showed that the model with product and substrate inhibition was the most accurate one. Therefore, the impact of immobilizations on beer fermentation would be assessed by this model (Table 1). The model parameters showed that the specific growth rate of IC were approximately $60 \%$ higher than the free cells. In terms of alcohol production, the results for specific rates of FC and IC were almost equal. The effect of product inhibition on FC was significant as the maximum inhibitory concentration of ethanol coincided with the maximum ethanol produced in this fermentation.

Table 1 Kinetic parameters for primary and secondary metabolism at temperature of main fermentation $12^{\circ} \mathrm{C}$ and temperature of maturation $14{ }^{\circ} \mathrm{C}$

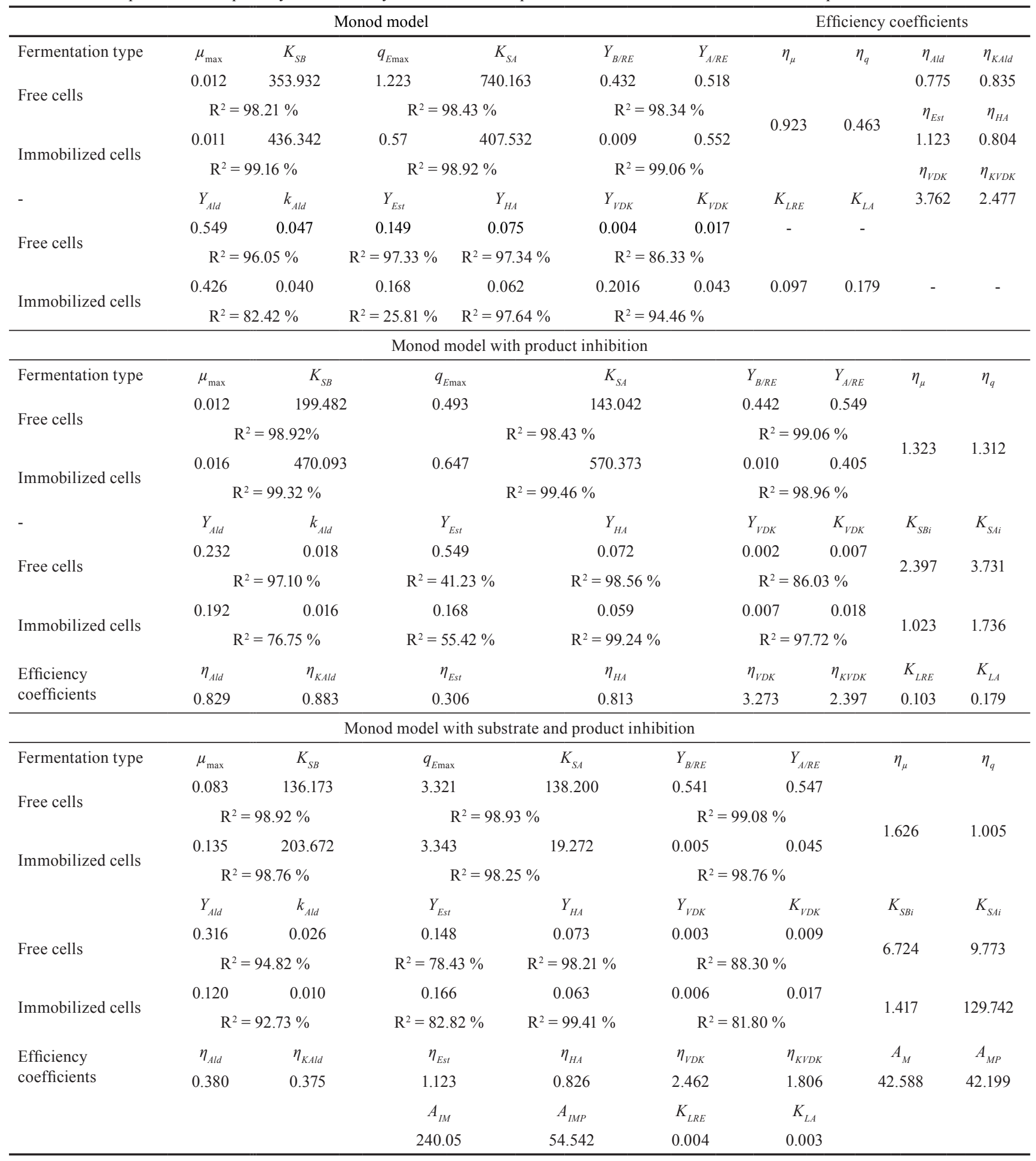


The ethanol had no inhibition effect on IC because the maximum inhibitory concentration of ethanol was approximately 8-times higher than ethanol produced. Therefore, it can be suggested that the immobilization protects yeast cells from product inhibition. Substrate inhibition had relatively low effect on both free and immobilized cells. Decreased aldehyde production as well as decreased aldehyde reduction for the IC was noted. Nevertheless, IC reduced aldehydes faster than free cells because the specific rate of aldehydes reduction depends on the current aldehydes concentration in beer and the biomass concentration. The specific rate of ester production of IC was $12 \%$ higher than the same for free cells. It can be explained that immobilization induces the inhibition of fatty acid synthesis, resulting in an accumulation of acyl-CoA that together with high levels of ethanol in immobilized cell systems enhance ethyl acetate formation [13]. The specific rate of fusel alcohols production for IC was lower than the free cells, which can be explained with mass (i.e. amino acids) transfer limitations. IC showed higher rates of VDKs production and reduction. The values of global mass transfer coefficients were almost equal (Table 1). It means that the product and the substrate diffusion rates were similar; therefore, the fermentation kinetics was influenced to a greater extent by the diffusion in the matrix.

The main disadvantage in the metabolites description in all three models was the low correlation of the model with the experimental results for the esters. The models for esters production assumed constant increase in ester concentration accumulation, while the experimental data showed decrease in esters concentrations at certain fermentation periods. This was mainly due to the hydrolysis of carbonic acid esters, as in the fermentation bottles, equipped with airlock system the carbonization was not stable, whereas industrial fermentation systems where the pressure increased in the maturation stage.

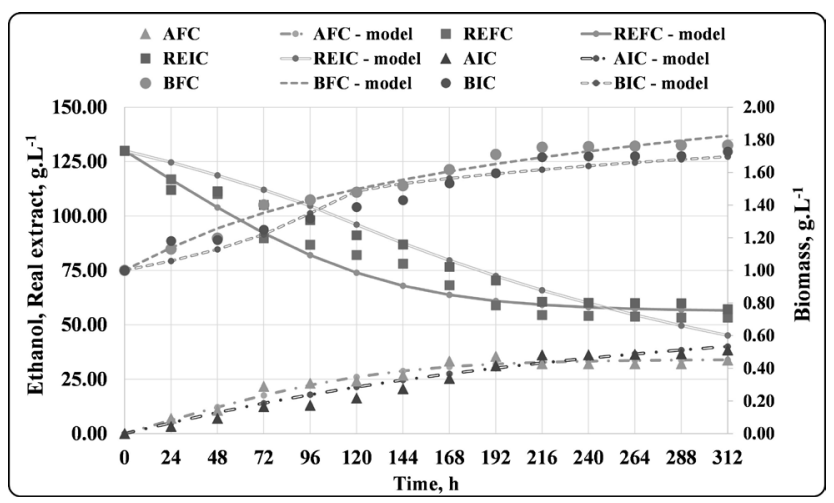

Finally, a sensory analysis was conducted on the beers with FC and IC. Two beers received similar scores for all the indicators. The beer with immobilized cells received better marks for "flowery" and "fruity", which was connected with higher esters concentration (Fig. 2).

\subsection{Main fermentation at $12{ }^{\circ} \mathrm{C}$; maturation at $8^{\circ} \mathrm{C}$}

Similarly to the previous variant, the main fermentation lasted between 96 and 120 hours, with sustained tendencies for slow start and faster completion of the process carried out with immobilized cells (Fig. 3). Kinetic models described the yeasts primary metabolism with high accuracy and there were no deviations from the trends already described (Table 2).

The main differences were observed in the secondary metabolites formation and reduction during maturation. The observed trends for ester production in the previous variant retained. The main amount of esters accumulated in the first 48-72 hours, after which no significant change in their concentration was observed. According to the most accurate model - Monod model with substrate and product inhibition - ester production was at almost the same rate in both types of fermentation (Table 2). In contrast to the previous variant, at the beginning of fermentation

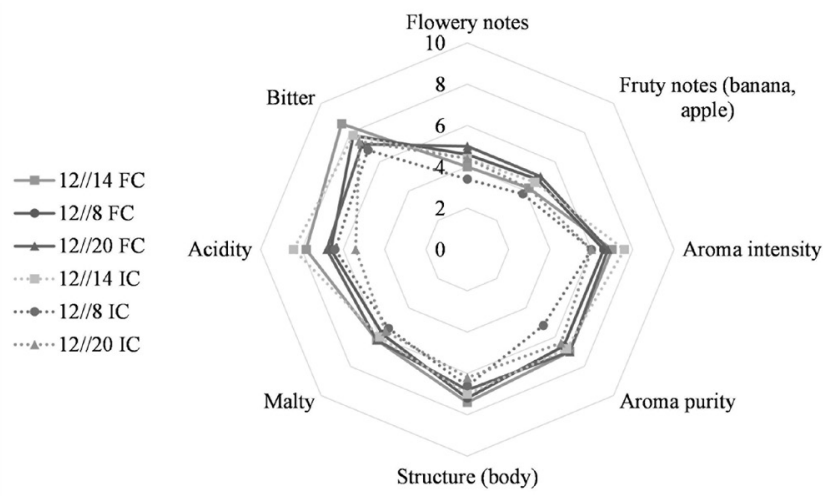

Fig. 2 Organoleptic assessment of experimental variants

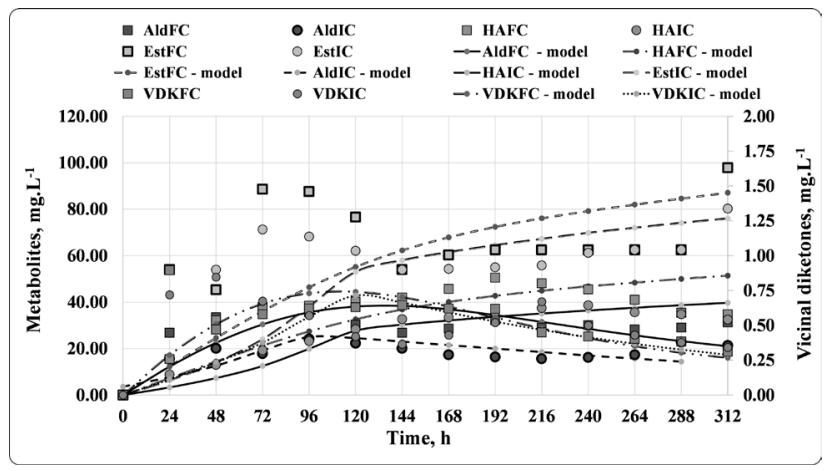

Fig. 3 The dynamics of the fermentation process with free and immobilized cells at $12{ }^{\circ} \mathrm{C} / 8^{\circ} \mathrm{C}$ 
Table 2 Kinetic parameters for primary and secondary metabolism at temperature of main fermentation $12^{\circ} \mathrm{C}$ and temperature of maturation $8{ }^{\circ} \mathrm{C}$

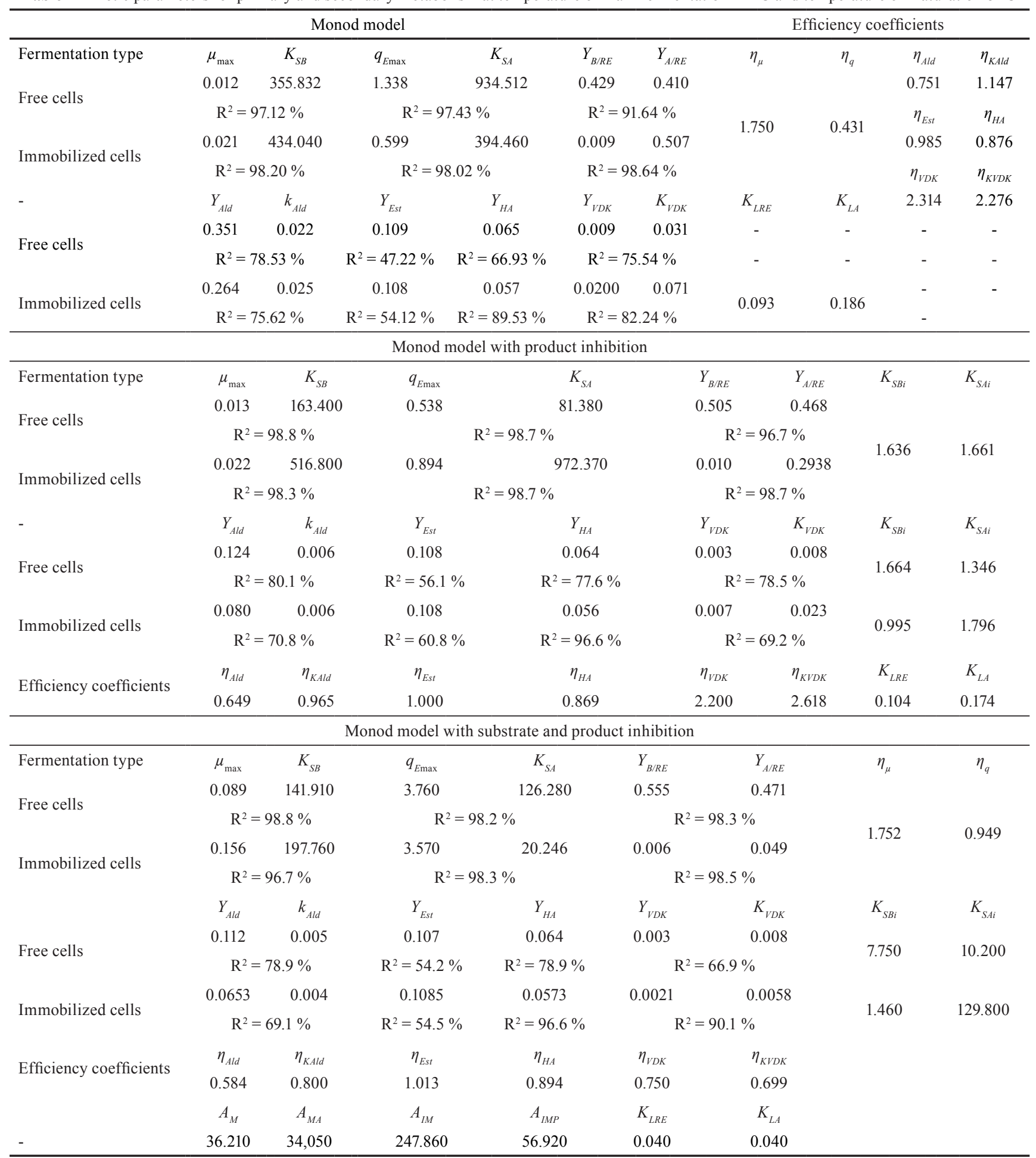

IC produced lower amount of higher alcohols but at the end of fermentation the concentrations were almost equal. The kinetic model with substrate and product inhibition showed about $10 \%$ reduced higher alcohol synthesis rate of the IC, which did not significantly affect the final concentrations of higher alcohols in the beer (Table 2).
Like the previous variant, FC produced more aldehydes, but the aldehyde reduction rate was equal for FC and IC, according to three models. This is the main prerequisite for higher aldehyde concentration in beer, produced with free cells. Unlike the previous variant, IC accumulated slightly lower VDKs and its peak was 24 hours later than 
free cells. This was described with highest accuracy of model with product and substrate inhibition. It's worth noting that only this model showed lower VDKs reduction rate for IC (Fig. 3).

Cold maturation was the main reason for an extended fermentation process that lasted more than 264 hours. The low maturation temperature was responsible for the increasing effect of product inhibition, especially due to a decrease in the maximum inhibitory concentration of ethanol in the FC fermentation. Immobilization protected the cells, and in this variant the concentration of a product that would inhibit yeast growth was approximately 6-times higher than the real ethanol concentration in beer. Similar to the previous variant the global coefficients of mass transfer were equal (Table 2).

The sensorial analysis carried out showed that the beer obtained with IC was evaluated lower than the conventional beer. The beer produced with IC has a suppressed aroma and a weak body structure (Fig. 2).

\subsection{Main fermentation at $12{ }^{\circ} \mathrm{C}$; maturation at $20{ }^{\circ} \mathrm{C}$}

Regarding the main fermentation the results were analogous to the previous two variants. The models showed high accuracy with respect to primary metabolism (Fig. 4). The main difference was related to the secondary metabolites and the reduction of maturation time. The increase in temperature resulted in a reduction in the total fermentation time between 24 hours and 48 hours compared to the first variant. This was economically feasible, but its effect on beer quality had to be studied in details. The ester synthesis occurred mainly during main fermentation and their concentration remained constant during maturation.

FC accumulated more esters but at the end of fermentation ester concentrations were approximately equal for free and immobilized cells. Regarding higher alcohols the IC produced slightly lower amounts because of mass transfer limitations. The data for carbonyl compounds showed second peak for aldehydes and VDKs during beer maturation.

A similar effect was observed by Naydenova [14], who considered the main reason for this phenomenon to be the accelerated assimilation of maltotriose at higher maturation temperatures. IC and FC produced similar amounts of VDKs but free cells reduced them faster. On the contrary, IC reduced aldehydes with higher rate than FC. Due to the differences observed in the secondary metabolites production, a lower correlation between models and experimental data was reported - between $75 \%$ and $80 \%$. Again, the model with product and substrate inhibition was the most accurate. Therefore, the impact of immobilizations on beer fermentation would be assessed by this model.

Data on the kinetic model confirmed the conclusions made previously. According to the Monod model with substrate and product inhibition the specific growth rate for immobilized cells was 1.9-times higher. In regard to ethanol production IC showed lower results because substantial substrate inhibition was observed. FC was more susceptible to product inhibition, because 40 g. $\mathrm{L}^{-1}$ of ethanol completely inhibited yeast growth. Regarding IC, the maximum inhibitory concentration of ethanol was 6 times higher. Like the previous variant, the data showed equality between the global coefficients of mass transfer for the Monod model with substrate and product inhibition.

The increase in maturation temperature significantly increased the production rates of higher alcohols, aldehydes and VDKs for IC compared to FC. Only the production rate of esters was lower for immobilized cells. The increased production rates of aldehydes and VDKs were at the basis of observed secondary peaks in the concentration of carbonyl compounds, which was a fermentation problem (Table 3).
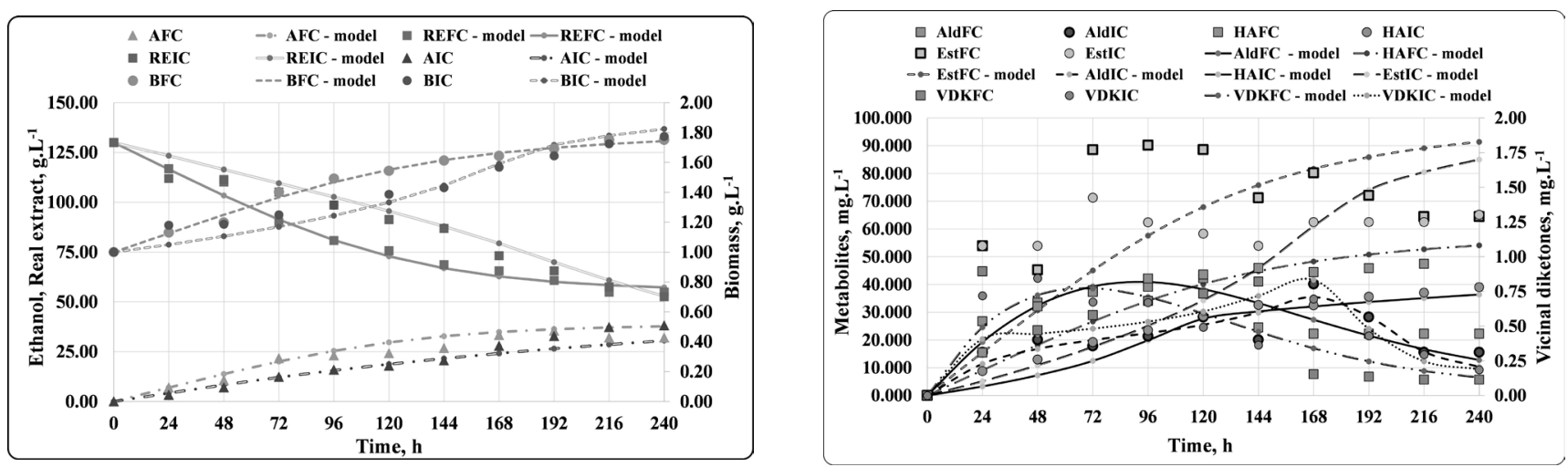

Fig. 4 The dynamics of the fermentation process with free and immobilized cells at $12{ }^{\circ} \mathrm{C} / 20{ }^{\circ} \mathrm{C}$ 
All these observations reflected in lower assessments of beer produced with IC (Fig. 2). It was evaluated lower in the aroma intensity and purity, the structure (body), and the acidity. Nevertheless, the final consumer rating did not differ significantly from a commercial beer (Fig. 2).

\subsection{Comparative assessment of kinetic parameters for} beer fermentation with FC and IC

The experimental data led to some more important conclusions regarding changes in metabolism of FC and IC. First, fermentation processes were best described with the

Table 3 Kinetic parameters for primary and secondary metabolism at temperature of main fermentation $12^{\circ} \mathrm{C}$ and temperature of maturation $20^{\circ} \mathrm{C}$

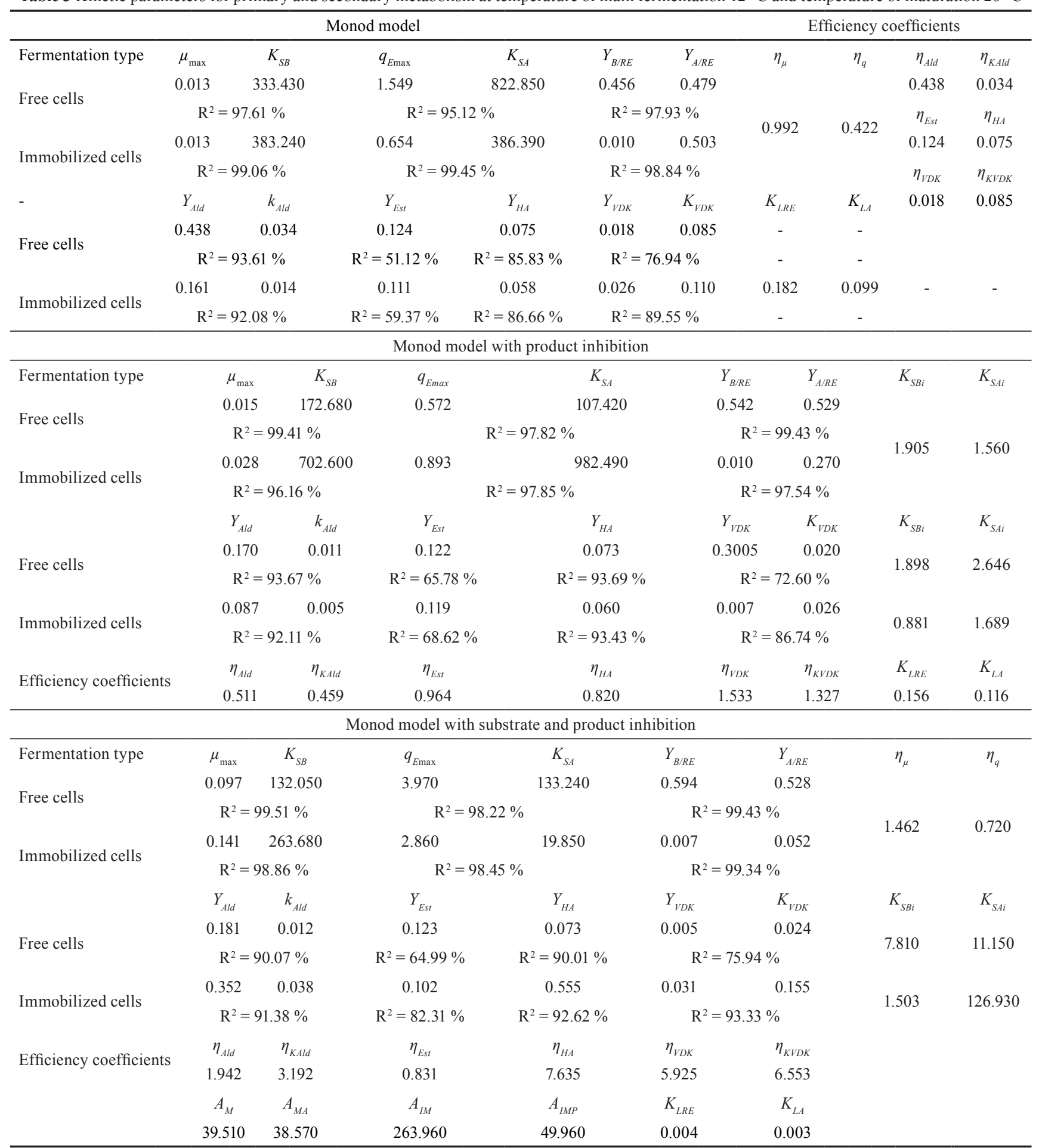


Monod model supplemented with product and substrate inhibition. On the one hand, this model was able to reflect the order of the sugars absorption (catabolic repression) and on the other hand, it showed that the yeast cells were susceptible to the ethanol inhibition, which in combination with the low temperatures led to prolonged fermentation. In this case, the presence of diffusion resistances in the IC system was the other reason for the increase in fermentation duration. The data shows that the specific growth rate increased with the increase in fermentation and maturation temperatures.

A comparison with the other three variants - constant temperature of fermentation $15{ }^{\circ} \mathrm{C}$; main fermentation at $10{ }^{\circ} \mathrm{C}$ and maturation at $14{ }^{\circ} \mathrm{C}$; main fermentation at $10{ }^{\circ} \mathrm{C}$ and maturation at $20{ }^{\circ} \mathrm{C}$ showed that the specific growth rate had the highest values at the constant fermentation temperature of $15^{\circ} \mathrm{C}[15]$. By contrast, the specific ethanol production rate was relatively constant, the tendency for a slight decrease in the variants $10^{\circ} \mathrm{C} / 14^{\circ} \mathrm{C}$ and $12{ }^{\circ} \mathrm{C} / 8^{\circ} \mathrm{C}$, then increase in the variants $12{ }^{\circ} \mathrm{C} / 14{ }^{\circ} \mathrm{C}$ and $12{ }^{\circ} \mathrm{C} / 20^{\circ} \mathrm{C}$ and another decrease in the variant $15{ }^{\circ} \mathrm{C} / 15^{\circ} \mathrm{C}$ with immobilized cells. The esters production showed two trends - the reduction of ester production at $12{ }^{\circ} \mathrm{C} / 8{ }^{\circ} \mathrm{C}$ and $12{ }^{\circ} \mathrm{C} /$ $20^{\circ} \mathrm{C}$, afterwards there was an increase in ester production in variants $12{ }^{\circ} \mathrm{C} / 14{ }^{\circ} \mathrm{C}$ and $10^{\circ} \mathrm{C} / 14^{\circ} \mathrm{C}$ and the highest results showed variant $15^{\circ} \mathrm{C} / 15^{\circ} \mathrm{C}$ with immobilized cells. Higher alcohols concentrations were poorly affected by temperature changes, with only in the variant $12{ }^{\circ} \mathrm{C} / 20^{\circ} \mathrm{C}$ with IC the higher alcohols concentrations were increased, probably due to local concentrations of these metabolites in the capsules at these fermentation temperatures. The variant $12{ }^{\circ} \mathrm{C} / 20^{\circ} \mathrm{C}$ with IC was also distinguished in the synthesis and reduction of carbonyl compounds. For aldehydes, the increase in fermentation temperature led to a reduction in aldehyde formation, while the reduction coefficients for

\section{References}

[1] Brányik, T., Vicente, A. A., Dostálek, P., Teixeira, J. A. "Continuous Beer Fermentation Using Immobilized Yeast Cell Bioreactor Systems", Biotechnology Progress, 21(3), pp. 653-663, 2005. https://doi.org/10.1021/bp050012u

[2] Shopska, V., Denkova, R., Kostov, G. "Beer Production with Encapsulated Yeast Cells", In: Salazar, W. H. (ed.) Beer: Production, Consumption and Health Effects, 1st ed., Nova Science Publishers Inc., Hauppauge, New York, USA, 2016, pp. 27-100.

[3] Willaert, R., Nedovic, V. A. "Primary beer fermentation by immobilised yeast - a review on flavour formation and control strategies", Journal of Chemical Technology and Biotechnology, 81(8), pp. 1353-1367, 2006. https://doi.org/10.1002/jctb.1582 aldehydes increased. The variants $12{ }^{\circ} \mathrm{C} / 14^{\circ} \mathrm{C}$ and $12{ }^{\circ} \mathrm{C}$ $120^{\circ} \mathrm{C}$ were optimal because of increased aldehyde reduction coefficients. The increase in temperature provoked an increase in the VDKs concentration while maintaining the reduction coefficients in relatively constant limits. In this case, variants $12{ }^{\circ} \mathrm{C} / 14{ }^{\circ} \mathrm{C}$ and $12{ }^{\circ} \mathrm{C} / 20^{\circ} \mathrm{C}$ were optimal because of fastest beer maturation.

\section{Conclusion}

The Monod model with substrate and product inhibition described with highest accuracy beer fermentation with IC and FC. The data showed the fermentation regime did not affect the primary metabolism. As a whole, IC showed higher biomass specific growth rate because of the significant effect on ethanol inhibition on free cells. The main reason for lower ethanol production rate of IC was the substrate inhibition. The accumulation of different yeast by-products was significantly influenced by the fermentation regime. Various trends in different fermentation regimens are observed for carbonyl compounds. The formation and reduction of aldehydes and VDKs increased with the increase of maturation temperatures for IC but for FC the highest yield and reduction coefficients for aldehydes were at maturation temperature $14{ }^{\circ} \mathrm{C}$. The increase in maturation temperature led to increase in fusel alcohol yield coefficient for both free and immobilized cells. In regard to ester synthesis, highest yield was at maturation temperature $14{ }^{\circ} \mathrm{C}$ for both FC and IC.

\section{Acknowledgement}

Research has been funded under Project No КП-06-M27/3 "Technological and microbiological approaches for the production of new types low-alcohol and non-alcoholic drinks with increased biological value" of National Science Fund, Bulgaria.

[4] Pires, E., Brányik, T. "By-products of Beer Fermentation", In: Biochemistry of Beer Fermentation, Springer Briefs in Biochemistry and Molecular Biology, 1st ed., Springer, Cham, Switzerland, 2015, pp. 51-80. https://doi.org/10.1007/978-3-319-15189-2 3

[5] Saerens, S. M. G., Delvaux, F., Verstrepen, K. J., Van Dijck, P., Thevelein, J. M., Delvaux, F. R. "Parameters Affecting Ethyl Ester Production by Saccharomyces cerevisiae during Fermentation", Applied and Environmental Microbiology, 74(2), pp. 454-461, 2008. https://doi.org/10.1128/AEM.01616-07

[6] Krogerus, K., Gibson, B. R. "125 ${ }^{\text {th }}$ Anniversary Review: Diacetyl and its control during brewery fermentation", Journal of The Institute of Brewing, 119(3), pp. 86-97, 2013.

https://doi.org/10.1002/jib.84 
[7] Djordjević, V., Willaert, R., Gibson, B., Nedović, V. "Immobilized Yeast Cells and Secondary Metabolites", In: Mérillon, J.-M., Ramawat, K. G (eds.) Fungal Metabolites, Reference Series in Phytochemistry, 1st ed., Springer, Cham, Switzerland, 2016, pp. 1-40.

https://doi.org/10.1007/978-3-319-19456-1_33-1

[8] Willaert, R. "The Beer Brewing Process: Wort Production and Beer Fermentation", In: Hui, Y. H. (ed.) Handbook of Food Products Manufacturing, 1st ed., John Wiley \& Sons, Inc., Hoboken, NJ, USA, 2006, pp. 443-506.

https://doi.org/10.1002/9780470113554.ch20

[9] Parcunev, I., Naydenova, V., Kostov, G., Yanakiev, Y., Popova, Z., Kaneva, M., Ignatov, I. "Modeling of Alcohol Fermentation in Brewing - Some Practical Approaches", In: $26^{\text {th }}$ European Conference on Modelling and Simulation, Koblenz, Germany, 2012, pp. 434-440.

https://doi.org/10.7148/2012-0434-0440

[10] European Brewery Convention "Analytica EBC", [online] Available at: https://brewup.eu/ebc-analytica/search [Accessed: 16 April 2019]

[11] Marinov, M. "Ръководство за анализ на високоалкохолни напитки и спирт" (Practical guide for analysis and control of alcoholic beverages and ethanol), 1st ed., Academy Publisher of UFT, Plovdiv, Bulgaria, 2010. (in Bulgarian)
[12] Petelkov, I., Lyubenova, V., Zlatkova, A., Shopska, V., Denkova, R., Kaneva, M., Kostov, G. "Encapsulation of brewing yeast in alginate / chitosan matrix: Kinetic characteristics of the fermentation process at a constant fermentation temperature", Comptes rendus de l'Académie bulgare des Sciences, 69(10), pp. 1355-1363, 2016.

[13] Shen, H.-Y., Moonjai, N., Verstrepen, K. J., Delvaux, F. R. "Impact of Attachment Immobilization on Yeast Physiology and Fermentation Performance", Journal of the American Society of Brewing Chemists, 61(2), pp. 79-87, 2003. https://doi.org/10.1094/ASBCJ-61-0079

[14] Naydenova, V. "Проучване на възможностите за получаване на пиво с имобилизирани дрожди" (A study of possibilities for beer production with immobilized yeast cells), $\mathrm{PhD}$ Thesis, University of Food Technologies, Plovdiv, Bulgaria, 2014. (in Bulgarian)

[15] Kostov, G., Denkova-Kostova, R., Shopska, V., Goranov, B. "Analytical approaches to determine the specific biomass growth rate in brewing", In: $33^{\text {th }}$ European Conference on Modelling and Simulation, Caserta, Italy, 2019. (in press) 